\title{
Serum Uric Acid Levels in Acute Ischemic Stroke: A Study of 100 Patients
}

\author{
Tushar B. Patil ${ }^{\mathrm{a}, \mathrm{c}}$, Amit S. Pasari ${ }^{\mathrm{a}}$, Kiran M. Sargar ${ }^{\mathrm{b}}$, Vinayak E. Shegokar ${ }^{\mathrm{a}}$, \\ Yogendra V. Bansod ${ }^{\text {a }}$, Mangesh B. Patil ${ }^{\mathrm{a}}$
}

\begin{abstract}
Background: It is unclear whether Serum Uric Acid (SUA) promotes or protects against the cerebrovascular disease. Present study was done to estimate uric acid levels in patients of acute ischemic stroke.
\end{abstract}

Methods: 100 cases of acute ischemic stroke were studied along with 100 controls. Risk factors for stroke were noted such as hypertension, diabetes mellitus, metabolic syndrome, smoking, and obesity. Serum uric acid levels were measured in cases and controls. Modified National Institute of Health (NIH) stroke scale score was calculated at admission and before discharge. Statistical analysis was performed with of SPSS 13.0 software.

Results: Out of 100 patients, 63 were males and 37 were females. Mean SUA level in cases was $6.48 \pm 1.92 \mathrm{mg} / \mathrm{dl}$ whereas it was 5.09 $\pm 1.07 \mathrm{mg} / \mathrm{dl}$ for controls. SUA values were higher among males than females, but this difference was not statistically significant $(\mathrm{P}$ $=0.085)$. The mean SUA in hypertensive subjects $(6.42 \pm 1.85 \mathrm{mg} /$ dl) was higher than that in normotensive subjects $(5.49 \pm 1.55 \mathrm{mg} /$ dl). There was a statistically significant difference between SUA levels in diabetic $(6.85 \pm 1.86 \mathrm{mg} / \mathrm{dl}$, Range $3.1-12 \mathrm{mg} / \mathrm{dl})$ and

Manuscript accepted for publication December 2, 2011

${ }^{a}$ Department of Medicine, Government Medical College, Nagpur, Maharashtra, India

${ }^{\mathrm{b}}$ Department of Radiodiagnosis, Government Medical College, Nagpur, Maharashtra, India

${ }^{c}$ Corresponding author: Tushar B. Patil, Plot no. 9, Rashtrasant Nagar, Godhani Road, Zingabai Takli, Nagpur, Maharashtra, India.

Email: dr.tushar42@rediffmail.com

doi:10.4021/jnr71w non-diabetic patients $(5.56 \pm 1.58 \mathrm{mg} / \mathrm{dl}$, Range $2.1-11 \mathrm{mg} / \mathrm{dl}))$ $(\mathrm{P}=0.00)$. Mean SUA in overweight patients was $6.48 \pm 1.65 \mathrm{mg} /$ dl (Range 2.1 - $9.9 \mathrm{mg} / \mathrm{dl}$ ) whereas it was $5.55 \pm 1.65$ (Range 2.1 - $12 \mathrm{mg} / \mathrm{dl}$ ) in patients who had a normal weight. The mean SUA in patients with metabolic syndrome was $6.82 \pm 1.62 \mathrm{mg} / \mathrm{dl}$ (Range $2.1-10 \mathrm{mg} / \mathrm{dl}$ ) and $5.45 \pm 1.59 \mathrm{mg} / \mathrm{dl}$ (Range $2.1-12 \mathrm{mg} / \mathrm{dl}$ ) for the subjects without metabolic syndrome. SUA levels were significantly higher among smokers compared to non smokers ( $6.36 \pm 1.78 \mathrm{vs}$. $5.69 \pm 1.67, \mathrm{P}=0.05)$. There was a significant positive correlation between SUA and NIH stroke scale score $(\mathrm{P}<0.05)$. SUA levels were significantly higher in the patients who succumbed as compared to those who were discharged from the hospital $(\mathrm{P}=0.00)$.

Conclusions: SUA can be used as a marker for increased risk of stroke. Furthermore, SUA can also be used for risk stratification after stroke.

Keywords: Serum uric acid; Acute ischemic stroke; Diabetes; Hypertension; Metabolic syndrome; Smoking

\section{Introduction}

The role of Serum Uric Acid (SUA) in the development of cardiovascular disease has been debated for over 50 years [1]. Several large studies have provided conflicting results regarding the clinical significance of elevated serum uric acid levels in cardiovascular or cerebrovascular diseases. Many studies including the NHANES study concluded that uric acid is an independent risk factor for development of cardiovascular and cerebrovascular diseases [2]. In contrast the Framingham Heart Study concluded that an association between hyperuricemia and cardiovascular diseases merely reflects the link between serum uric acid and other risk factors, including hypertension, renal disease, elevated lipoprotein levels and the use of diuretics [3].

Therefore it is unclear whether SUA promotes or protects against the development of cerebrovascular disease or simply acts as a passive marker of increased risk.

Amidst this controversy and lack of Indian data, it was decided to carry out the present study with the aim of studying uric acid levels in patients of acute ischemic stroke. 
Table 1. Comparison of Conventional Risk Factors for Ischemic Stroke (Confounding Variables) Between Cases and Controls (Univariate Analysis)

\begin{tabular}{|c|c|c|c|c|c|}
\hline Variable & & Case & Control & Total & P value \\
\hline Age (years) & & $60.05 \pm 9.98$ & $60.32 \pm 10.11$ & $60.18 \pm 10.02$ & 0.850 \\
\hline Hypertension & No & 51 & 11 & 138 & $\begin{array}{l}\chi^{2}=37.40 \\
\text { OR }=8.4295 \% \\
\text { C.I. }=4.02-17.63 \\
P=0.00\end{array}$ \\
\hline Diabetes mellitus & Yes & 23 & 89 & 166 & $\begin{array}{l}\chi^{2}=5.103 \\
\text { OR }=2.4195 \% \\
\text { C.I }=1.10-5.27 \\
P=0.023\end{array}$ \\
\hline $\begin{array}{l}\text { Metabolic } \\
\text { syndrome }\end{array}$ & No & 40 & 92 & 152 & $\begin{array}{l}\chi^{2}=28.07 \\
O R=7.6695 \% \\
\text { C.I. }=3.35-17.50 \\
P=0.000\end{array}$ \\
\hline Smoking & Yes & 80 & 92 & 172 & $\begin{array}{l}\chi^{2}=5.98 \\
O R=2.8795 \% \\
\text { C.I. }=1.20-6.88 \\
P=0.014\end{array}$ \\
\hline Obesity & Yes & 56 & 94 & 150 & $\begin{array}{l}\chi^{2}=38.57 \\
\text { OR }=12.3195 \% \\
\text { C.I. }=4.93-30.73 \\
P=0.000\end{array}$ \\
\hline BMI & & $25.13 \pm 3.13$ & $22.93 \pm 2.88$ & & $\begin{array}{l}t=5.178 \\
P=0.00\end{array}$ \\
\hline
\end{tabular}

\section{Material and Methods}

This case control study was performed from November 2007 to November 2009. A total of 100 cases of acute ischemic stroke were studied. 100 age and sex matched healthy controls were also enrolled in the study.

\section{Selection of cases}

Cases of acute ischemic stroke admitted to Medicine wards were included in the study. Stroke was defined as per the WHO (World Health Organization) definition, 'a syndrome of rapidly developing clinical signs of focal or global neurological disturbance lasting for more than 24 hours'. Only
CT brain or MRI brain proved cases of acute ischemic stroke were included in the study.

\section{Exclusion criteria}

Subjects with following conditions were excluded from the study: 1)Patients with a known or possible cardiac source of emboli (atrial fibrillation, valvular heart disease, patients receiving anticoagulant treatment; 2) Duration of symptoms more than 48 hours; 3) Past history of vascular disease (previous stroke, angina, myocardial infarction, revascularizations, peripheral artery disease); 4) Patients receiving drugs affecting SUA levels (diuretics, losartan, allopurinol, probenecid, atorvastatin, fenofibrate); 5) Active infections; 
Table 2. Comparison of Serum Uric Acid Levels in Cases and Controls

\begin{tabular}{llll}
\hline & Cases & Controls & P value \\
\hline Mean SUA & $6.48 \pm 1.92$ & $5.09 \pm 1.07$ & 0.00 \\
Range & $2.1-12$ & $2.1-8$ \\
Median & 6.55 & 4.9 \\
\hline
\end{tabular}

6) Malignancy; 7) Renal or liver disease; 8) Thyroid dysfunction; 9) Chronic obstructive pulmonary disease; 10) Chronic inflammatory bowel disease; 11) Excessive alcohol consumption.

\section{Selection of controls}

Age and sex matched healthy control was selected for every case.

\section{Definitions}

Hypertension was defined as a blood pressure of $\geq 140 / 90$ $\mathrm{mm}$ of Mercury on 2 or more occasion or ongoing treatment for systemic hypertension or previously diagnosed cases of systemic hypertension.

Diabetes mellitus was defined as fasting blood sugar of $\geq 126 \mathrm{mg} / \mathrm{dl}$ or history of receiving treatment for diabetes mellitus or previously diagnosed diabetes mellitus.

Metabolic syndrome was defined as per the NCEP ATP III guidelines [4]. The patients having 3 or more of the following were classified as having metabolic syndrome: 1) Central obesity: waist circumference $>102 \mathrm{~cm}$ for male and $>88 \mathrm{~cm}$ for female; 2) Hypertriglyceridemia: Triglyceride $\geq$ $150 \mathrm{mg} / \mathrm{dl}$ or specific medications; 3) Low HDL cholesterol: $<40 \mathrm{mg} / \mathrm{dl}$ for male and $<50 \mathrm{mg} / \mathrm{dl}$ for female or specific medications; 4) Hypertension: Blood pressure $\geq 130 \mathrm{~mm}$ systolic or $\geq 85 \mathrm{~mm}$ diastolic or specific medications; 5) Fasting plasma glucose $\geq 100 \mathrm{mg} / \mathrm{dl}$ or specific medications or previously diagnosed type 2 diabetes mellitus.

Person who smoked at least 10 cigarettes per day for 6 months/more or the one who has smoked daily for more than 1 year or more regardless of the number of cigarettes smoked per day was considered as smoker [5]. A BMI (Body Mass Index) of $\geq 25$ was taken as marker of being overweight.

\section{Biochemical measurements}

1) Serum uric acid was measured with the Uricase method $[6-8]$; 2) All other biochemical measurements were performed as per the standard procedures.

Modified National Institute of Health (NIH) stroke scale score was calculated for all the patients of stroke at the time of admission and before discharge from hospital.

\section{Statistical analysis}

Statistical analysis was performed with the help of SPSS 13.0 software. It included the usual descriptive and univariate analysis. Student $t$ test was used to compare continuous variables and $\chi^{2}$ test was used to compare categorical variables. Unadjusted odds ratio with $95 \%$ confidence interval

Table 3. Multiple Logistic Regression Analysis Showing Association of Various Risk Factors With Ischemic Stroke

\begin{tabular}{lccccc}
\hline Risk factor & Odds ratio & Z value & \multicolumn{9}{c}{$\mathbf{9 5 \%}$ Confidence interval } & P value \\
\hline Hypertension & 0.152 & -3.936 & -2.824 & -0.947 & 0.000 \\
Diabetes Mellitus & 0.960 & -0.062 & -1.339 & 1.257 & 0.951 \\
Metabolic syndrome & 0.655 & -0.628 & -1.741 & 0.896 & 0.530 \\
Smoking & 0.405 & -1.966 & -1.805 & -0.003 & 0.049 \\
SUA & 1.487 & 3.625 & 0.182 & 0.611 & 0.000 \\
Obesity & 0.116 & -3.636 & -3.321 & -0.995 & 0.000 \\
\hline
\end{tabular}


Table 4. Relationship of SUA With Age

\begin{tabular}{ccc}
\hline Age & No. of patients $(\mathbf{n}=\mathbf{2 0 0})$ & Mean SUA \\
\hline$<50$ & 26 & $5.43 \pm 1.98$ \\
$50-59$ & 65 & $5.87 \pm 1.69$ \\
$60-69$ & 69 & $5.77 \pm 1.69$ \\
$\geq 70$ & 40 & $5.88 \pm 1.56$ \\
\hline
\end{tabular}

and $\mathrm{P}$ value were calculated.

Multivariate analysis was performed to study the association of SUA with acute ischemic stroke in multivariate context. Ischemic stroke was taken as dichotomous independent outcome variable and conventional risk factors (e.g. hypertension, diabetes mellitus etc.) as dependent predictor variables. $P$ value less than 0.05 was taken as significant.

The study protocol was approved by the Institutional Ethics Committee.

\section{Results}

Out of 100 patients studied, 63 were males and 37 were females. Male: female ratio was 1.7: 1. The controls were appropriately age and sex matched. The mean age of cases was $60.05 \pm 9.98$ and the range was 36 to 86 , whereas the mean age of controls was $60.32 \pm 10.11$ (with the range from 36 to 87 years). The difference between the two groups was not statistically significant $(\mathrm{P}=0.85)$.

Comparison of conventional risk factors for ischemic stroke (confounding variables) between cases and controls is shown in Table 1.

Mean SUA level in cases was $6.48 \pm 1.92 \mathrm{mg} / \mathrm{dl}$ whereas it was $5.09 \pm 1.07 \mathrm{mg} / \mathrm{dl}$ for controls. Mean SUA level was significantly higher in cases as compared to controls $(\mathrm{P}=$ 0.00) (Table 2).

Table 3 shows the association of various risk factors with ischemic stroke in the multiple logistic regression analysis. This analysis shows that hypertension, smoking, and obesity were found to be independently associated with ischemic stroke. It was also found that serum uric acid was also independently associated with ischemic stroke.

The SUA levels increased with increasing age but this correlation was not statistically significant (Table 4).

The mean SUA was $5.94 \pm 1.72$ (Range 2.1 - 12) mg/ $\mathrm{dl}$ for males and $5.51 \pm 1.64$ (Range $2.1-10) \mathrm{mg} / \mathrm{dl}$ for females. SUA values were higher among males as compared to females, but this difference was not statistically significant $(\mathrm{P}=0.085)$.

The mean SUA in hypertensive subjects $(6.42 \pm 1.85$ $\mathrm{mg} / \mathrm{dl}$ ) was higher than that in normotensive subjects (5.49 $\pm 1.55 \mathrm{mg} / \mathrm{dl}$ ). This difference was statistically significant ( $\mathrm{P}$ $=0.00$ ).

There was a statistically significant difference between SUA levels in diabetic $(6.85 \pm 1.86 \mathrm{mg} / \mathrm{dl}$, Range $3.1-12$ $\mathrm{mg} / \mathrm{dl})$ and non-diabetic patients $(5.56 \pm 1.58 \mathrm{mg} / \mathrm{dl}$, Range $2.1-11 \mathrm{mg} / \mathrm{dl}))(\mathrm{P}=0.00)$.

Mean SUA in overweight patients was $6.48 \pm 1.65 \mathrm{mg} /$ $\mathrm{dl}$ (Range $2.1-9.9 \mathrm{mg} / \mathrm{dl}$ ) whereas it was $5.55 \pm 1.65$ (Range

Table 5. Relationship of SUA With HDL Cholesterol

\begin{tabular}{ccc}
\hline SUA $(\mathbf{m g} / \mathbf{d l})$ & Mean HDL cholesterol $(\mathbf{m g} / \mathbf{d l})$ & \\
\hline$<5$ & $49.19 \pm 8.71$ & \\
$5-5.9$ & $46.74 \pm 7.67$ & $\mathrm{r}=-0.334$ \\
$6-6.9$ & $44.14 \pm 9.99$ & $\mathrm{p}=0.001$ \\
$\geq 7$ & $41.11 \pm 10.17$ & \\
\hline
\end{tabular}


Table 6. Relationship of SUA With Serum Triglyceride Level

\begin{tabular}{ccc}
\hline SUA $(\mathbf{m g} / \mathbf{d l})$ & Mean triglyceride level $(\mathbf{m g} / \mathbf{d l})$ & \\
\hline$<5$ & $123.56 \pm 33.91$ & \\
$5-5.9$ & $126.27 \pm 43.11$ & $\mathrm{r}=0.294$ \\
$6-6.9$ & $147.97 \pm 42.78$ & $\mathrm{p}=0.001$ \\
$\geq 7$ & $156.90 \pm 45.40$ & \\
\hline
\end{tabular}

$2.1-12 \mathrm{mg} / \mathrm{dl}$ ) in patients who had a normal weight. There was a statistically significant difference in SUA levels in obese and non obese subjects $(\mathrm{P}=0.001)$.

The mean SUA in patients fulfilling the criteria for metabolic syndrome was $6.82 \pm 1.62 \mathrm{mg} / \mathrm{dl}$ (Range $2.1-10$ $\mathrm{mg} / \mathrm{dl}$ ) and it was $5.45 \pm 1.59 \mathrm{mg} / \mathrm{dl}$ (Range $2.1-12 \mathrm{mg} / \mathrm{dl}$ ) for the subjects who did not fulfil the criteria for metabolic syndrome. This difference was statistically significant $(\mathrm{P}=$ 0.00). SUA levels were significantly higher among smokers as compared to non smokers $(6.36 \pm 1.78$ vs. $5.69 \pm 1.67, \mathrm{P}$ $=0.05$ ).

Table 5 shows that there was a significant inverse correlation between SUA and HDL cholesterol.

A significant positive correlation between SUA and serum triglycerides was also observed in the present study (Table 6).

Mean SUA level was lower in the patients with lacunar stroke as compared to the patients with larger infarcts $(6.16$ $\pm 1.68 \mathrm{mg} / \mathrm{dl}$ vs. $6.73 \pm 2.07 \mathrm{mg} / \mathrm{dl})$. But this difference was not statistically significant as the $(\mathrm{P}>0.05$.

The correlation between SUA and NIHSS score was studied with the help of Spearman rank correlation. It was found that there was a significant positive correlation between SUA and NIH stroke scale score on admission as well as at the time of discharge ( $\mathrm{P}<0.05$ for both) (Table 7$)$.

Mean SUA for discharged patients $(\mathrm{n}=87)$ was $6.16 \pm$ $1.68 \mathrm{mg} / \mathrm{dl}$ and it was $8.60 \pm 2.16 \mathrm{mg} / \mathrm{dl}$ for the patients who died in the hospital $(\mathrm{n}=13)$. SUA levels were significantly higher in the patients who succumbed as compared to those who were discharged from the hospital $(\mathrm{P}=0.00)$.

\section{Discussion}

The well recognized risk factors for stroke like age, smoking, diabetes, hypertension, metabolic syndrome explain only a part of the cases. Hence a search for other risk factors is the need of the hour. This study was conducted to study the role of serum uric acid in acute ischemic stroke and its effect on stroke outcome.

The male to female ratio was $1.7: 1$. The mean age of the cases was $60.05 \pm 9.98$ years with the range of 36 to 86 years.

These findings are consistent with the data published by Pandiyan et al [9] who observed a male: female ratio of 1.9:1 and mean age of stroke patients as $61.7 \pm 13.4$ years.

The mean SUA levels were higher among males than females but this difference did not attain statistical significance.

Pearce et al (1969) observed higher SUA values in males as compared to females $(5.28 \pm 0.66$ vs. $4.47 \pm 0.78 \mathrm{mg} / \mathrm{dl})$ [10]. B. Longo-Mbenza et al [11] found significantly higher SUA level in males $(6.6 \pm 7$ vs. $5.8 \pm 6 \mathrm{mg} / \mathrm{dl}, \mathrm{P}<0.01)$. Similar results were obtained in the study by Milionis et al

Table 7. Relationship of SUA With National Institute of Health Stroke Scale (NIHSS) Score

\begin{tabular}{|c|c|c|c|}
\hline & & NIHSSS on admission & NIHSSS on discharge \\
\hline \multirow{3}{*}{ Serum uric acid } & Number of patients & 100 & 87 \\
\hline & r value & 0.407 & 0.398 \\
\hline & $\mathrm{P}$ value & 0.000 & 0.000 \\
\hline
\end{tabular}


[12] and in the Rotterdam study [13] (348 vs.302 $\mu \mathrm{mol} / \mathrm{L}$ ). Framingham heart study [3] also showed higher SUA levels in males.

It was also found that SUA levels among hypertensive patients were significantly higher as compared to normotensive patients $(6.42 \pm 1.85$ vs. $5.49 \pm 1.55 \mathrm{mg} / \mathrm{dl}, \mathrm{P}<0.05)$.

Milionis et al [12] observed that SUA levels were higher in hypertensive subjects compared with nonhypertensives $(5.4 \pm 1.6 \mathrm{mg} / \mathrm{dl}$ vs. $5.0 \pm 1.6 \mathrm{mg} / \mathrm{dl}, \mathrm{P}=0.04)$. Lehto et al [14] also found that the prevalence of hypertension among hyperuricemic subjects was higher as compared to the patients with SUA levels in the normal range $(67.3 \%$ vs. $41.2 \%$, $\mathrm{P}<0.001)$.

We found that SUA levels in patients suffering from diabetes mellitus were significantly higher as compared to those in non diabetic subjects $(6.85 \pm 1.86$ vs. $5.56 \pm 1.58 \mathrm{mg} / \mathrm{dl}$, $\mathrm{P}<0.05)$.

Our findings are in accordance with the findings of Longo-Mbenza et al [11] who observed significantly higher frequency of hyperuricemia among diabetic patients.

In our study, correlation between obesity and ischemic stroke was found to be independent on multiple logistic regression analysis $(\mathrm{OR}=0.116, \mathrm{z}=-3.636,95 \%$ C.I. $=-3.321$ to $-0.995, \mathrm{P}<0.05)$.

Per Harmesen et al. [15] also found that obesity is a risk factor for stroke $(\mathrm{OR}=2.23,95 \%$ C.I. $=1.83-2.72)$. Also, Milionis et al. [12] who found significantly higher levels of SUA among overweight patients $(\mathrm{BMI}>25)$ as compared to non-obese patients $(5.4 \pm 1.6$ vs. $4.9 \pm 1.5 \mathrm{mg} / \mathrm{dl}, \mathrm{P}=0.004)$.

In this study it was observed that mean SUA level in smokers was significantly higher as compared to non smokers $(6.36 \pm 1.78$ vs. $5.69 \pm 1.67 \mathrm{mg} / \mathrm{dl}, \mathrm{P}=0.05)$.

Similarly, Strasak et al. [16] also observed a positive correlation between SUA and smoking $(\mathrm{r}=0.11, \mathrm{P}<0.001)$. Mozos et al [17] also found that SUA levels were significantly higher in smokers as compared to non smokers $(5.7 \pm$ 1.3 vs. $5.0 \pm 1.1 \mathrm{mg} / \mathrm{dl}, \mathrm{P}<0.05)$.

In our study, we found a significant inverse correlation between SUA levels and HDL cholesterol, and a positive correlation between SUA and serum triglyceride levels $(\mathrm{r}=$ $-0.334, \mathrm{P}=0.001$ for HDL and $\mathrm{r}=0.294, \mathrm{P}=0.001$ for triglycerides).

Lehto et al. [14] concluded that SUA was significantly associated with HDL cholesterol $(\mathrm{r}=-0.25, \mathrm{P}<0.01)$ and triglyceride levels $(\mathrm{r}=0.14, \mathrm{P}<0.01)$.

Bansal et al. [18] found a significant correlation between SUA and triglyceride $(\mathrm{P}<0.05)$.

Our findings correlate with the above mentioned studies.

We found that stroke patients had a significantly higher SUA levels when compared to the controls $(6.48 \pm 1.92 \mathrm{mg}$ / dl vs. $5.09 \pm 1.07 \mathrm{mg} / \mathrm{dl}, \mathrm{P}<0.05)$. On multiple regression analysis, correlation of SUA with ischemic stroke was found to be independent of other major risk factors for stroke.

These findings are in accordance with most of the data published worldwide.

Milionis et al. [12] observed that the SUA levels were significantly higher in stroke patients compared with controls $(5.6 \pm 1.7 \mathrm{mg} / \mathrm{dl}$ vs. $4.8 \pm 1.4 \mathrm{mg} / \mathrm{dl}, \mathrm{P}<0.001)$. Srikrishna R and Suresh DR [19] found that serum uric acid levels were significantly higher in cases as compared to controls $(6.56 \pm 0.73$ vs. $4.66 \pm 0.47, \mathrm{P}<0.05)$. In The Rotterdam study [13], high serum uric acid levels were associated with the risk of stroke.

We used National Institute of Health Stroke Scale (NIHSS) to quantify stroke severity. It has been proved in earlier studies that higher NIHSS score portends poor prognosis following stroke $[20,21]$. In the present study there was a significant correlation between SUA level and NIHSS score on admission $(\mathrm{r}=0.407, \mathrm{P}<0.001)$. NIHSS scores on discharge also correlated significantly with SUA levels $(\mathrm{r}=0.398, \mathrm{P}<$ 0.001 )

SUA levels were also higher in patients with large artery stroke as compared to those with lacunar stroke but this difference was not found to be statistically significant $(6.73 \pm$ 2.07 vs. $6.16 \pm 1.68 \mathrm{mg} / \mathrm{dl}, \mathrm{P}=0.145)$.

In our study, out of 100 patients, 13 patients died and remaining 87 patients were discharged from the hospital. The mean SUA levels were significantly higher in the patients who succumbed as compared to the patients who were alive at discharge $(8.60 \pm 2.16$ vs. $6.16 \pm 1.68 \mathrm{mg} / \mathrm{dl}, \mathrm{P}<0.05)$.

Karagiannis et al. [5] found an independent relationship between higher SUA levels on admission and death $(\mathrm{OR}=$ $1.37,95 \%$ C.I. $=1.13-1.67, \mathrm{P}=0.001)$. Weir et al [20] noted that higher serum urate value was significantly associated with bad outcome $(\mathrm{OR}=0.78$ per additional $0.1 \mathrm{mmol} / \mathrm{L}$; $95 \%$ C.I. $=0.67$ - 0.91). Mozos et al. [17] also found that the patients who died had a significantly higher SUA values as compared to those who were discharged home $(9.5 \pm 3 \mathrm{mg} /$ dl vs. $6.9 \pm 4 \mathrm{mg} / \mathrm{dl}, \mathrm{P}=0.003)$.

Only one study that was done by Chammoro et al. [22] found that higher levels of SUA at admission were associated with better outcome after stroke.

The findings of our study are in accordance with all but one study mentioned above. From the above discussion, it is evident that SUA levels are associated with increased risk for stroke as well as with poor short term and long term prognosis after stroke.

SUA is one of the major aqueous antioxidant in the human beings and constitutes as much as two third of the plasma free radical scavenging ability. It is therefore prudent to expect that SUA should have a protective role in stroke. But as discussed above only one study [22] has found that higher SUA level may be neuroprotective in patients with stroke. An explanation to this comes from the study which showed that SUA can work as a pro-oxidant under certain circumstances, particularly if the levels of other antioxidants (like ascorbate) are low [23]. Various studies have also showed that uric acid can result in endothelial dysfunction 
which can lead to vascular diseases [24, 25]. SUA can also promote LDL cholesterol in vitro [26]. An association between SUA levels and inflammatory markers has also been discovered [27-29]. Uric acid has also been found in the atherosclerotic plaques. Another putative mechanism involves the role of xanthine oxidase; higher SUA levels might reflect an increased activity of xanthine oxidase. The action of xanthine oxidase leads to generation of superoxide anions and the reactive oxygen species in human vasculature [30, 31]. Also, allopurinol, a xanthine oxidase inhibitor, was found to reduce inflammatory markers in stroke survivors [32].

Thus our study concludes that SUA can be used as a marker for increased risk of stroke. Furthermore, SUA can also be used for risk stratification after stroke.

Further long term prospective studies are needed to establish the role of SUA in ischemic stroke. Also, trial of SUA lowering drugs in stroke patients as well as in those at increased risk of stroke can be worth considering.

\section{Grant Support}

NIL.

\section{Conflicts of Interest}

NIL.

\section{Institution Where Work was Performed}

Department of Medicine, Government Medical College, Nagpur, Maharashtra, India

Pin Code-440003.

\section{References}

1. Gertler MM, Garn SM, Levine SA. Serum uric acid in relation to age and physique in health and in coronary heart disease. Ann Intern Med. 1951;34(6):1421-1431.

2. Fang J, Alderman MH. Serum uric acid and cardiovascular mortality the NHANES I epidemiologic follow-up study, 1971-1992. National Health and Nutrition Examination Survey. JAMA. 2000;283(18):2404-2410.

3. Culleton BF, Larson MG, Kannel WB, Levy D. Serum uric acid and risk for cardiovascular disease and death: the Framingham Heart Study. Ann Intern Med. 1999;131(1):7-13.

4. Third Report of the National Cholesterol Education Program (NCEP) Expert Panel on Detection, Evaluation, and Treatment of High Blood Cholesterol in Adults (Adult Treatment Panel III) Final Report. Circulation
2002;106:314.

5. Karagiannis A, Mikhailidis DP, Tziomalos K, Sileli M, Savvatianos S, Kakafika A, Gossios T, et al. Serum uric acid as an independent predictor of early death after acute stroke. Circ J. 2007;71(7):1120-1127.

6. Fossati P, Prencipe L, Berti G. Use of 3,5-dichloro-2hydroxybenzenesulfonic acid/4-aminophenazone chromogenic system in direct enzymic assay of uric acid in serum and urine. Clin Chem. 1980;26(2):227-231.

7. Trinder P. Ann. Clinical Biochemistry 1961. 6: 24.

8. International Federation of Clinical Chemistry - Clinical Chemistry Acta. 1978. 87/3: 459F.

9. Surveillance of stroke: WHO stepwise approach: A Chennai stroke unit report. Arjundas D, Pandiyan U, Arjundas G, Henry B. Annals of Indian Academy of Neurology, 2007; vol. 10; issue 3.

10. Pearce J, Aziz H. Uric acid and plasma lipids in cerebrovascular disease. I. Prevalence of hyperuricaemia. $\mathrm{Br}$ Med J. 1969;4(5675):78-80.

11. Longo-Mbenza B, Luila EL, Mbete P, Vita EK. Is hyperuricemia a risk factor of stroke and coronary heart disease among Africans? Int J Cardiol. 1999;71(1):17-22.

12. Milionis HJ, Kalantzi KJ, Goudevenos JA, Seferiadis K, Mikhailidis DP, Elisaf MS. Serum uric acid levels and risk for acute ischaemic non-embolic stroke in elderly subjects. J Intern Med. 2005;258(5):435-441.

13. Bos MJ, Koudstaal PJ, Hofman A, Witteman JC, Breteler MM. Uric acid is a risk factor for myocardial infarction and stroke: the Rotterdam study. Stroke. 2006;37(6):1503-1507.

14. Lehto S, Niskanen L, Ronnemaa T, Laakso M. Serum uric acid is a strong predictor of stroke in patients with non-insulin-dependent diabetes mellitus. Stroke. 1998;29(3):635-639.

15. Harmsen P, Lappas G, Rosengren A, Wilhelmsen L. Long-term risk factors for stroke: twenty-eight years of follow-up of 7457 middle-aged men in Goteborg, Sweden. Stroke. 2006;37(7):1663-1667.

16. Strasak A, Ruttmann E, Brant L, Kelleher C, Klenk J, Concin H, Diem G, et al. Serum uric acid and risk of cardiovascular mortality: a prospective long-term study of 83,683 Austrian men. Clin Chem. 2008;54(2):273-284.

17. Mozos I, Chiulana C, Goruna C, Costeab S. Serum uric acid in stroke. Annals of West University of Timisoara, Series of Chemistry 16 (2) (2007) 227 - 236.

18. Bansal BC, Gupta RR, Bansal MR, Prakash C. Serum lipids and uric acid relationship in ischemic thrombotic cerebrovascular disease. Stroke. 1975;6(3):304-307.

19. Shrikrishna R, Suresh DR. Biochemical study of antioxidant profile in acute ischemic stroke. British Journal of Medical Practitioners 2009:2(1) 35-37.

20. Weir CJ, Muir SW, Walters MR, Lees KR. Serum urate as an independent predictor of poor outcome and future vascular events after acute stroke. Stroke. 
2003;34(8):1951-1956.

21. Newman EJ, Rahman FS, Lees KR, Weir CJ, Walters MR. Elevated serum urate concentration independently predicts poor outcome following stroke in patients with diabetes. Diabetes Metab Res Rev. 2006;22(1):79-82.

22. Chamorro A, Obach V, Cervera A, Revilla M, Deulofeu $\mathrm{R}$, Aponte JH. Prognostic significance of uric acid serum concentration in patients with acute ischemic stroke. Stroke. 2002;33(4):1048-1052.

23. Abuja PM. Ascorbate prevents prooxidant effects of urate in oxidation of human low density lipoprotein. FEBS Lett. 1999;446(2-3):305-308.

24. Waring WS, Webb DJ, Maxwell SRJ. Effect of local hyperuricaemia on endothelial function in the human forearm vascular bed. Br J Clin Pharmacol 2000; 49: 511P.

25. Corry DB, Eslami P, Yamamoto K, Nyby MD, Makino $\mathrm{H}$, Tuck ML. Uric acid stimulates vascular smooth muscle cell proliferation and oxidative stress via the vascular renin-angiotensin system. J Hypertens. 2008;26(2):269275.

26. Bagnati M, Perugini C, Cau C, Bordone R, Albano E, Bellomo G. When and why a water-soluble antioxidant becomes pro-oxidant during copper-induced low-density lipoprotein oxidation: a study using uric acid. Biochem J. 1999;340 ( Pt 1):143-152.

27. Duff GW, Atkins E, Malawista SE. The fever of gout: urate crystals activate endogenous pyrogen production from human and rabbit mononuclear phagocytes. Trans Assoc Am Physicians. 1983;96:234-245.

28. Nakanishi N, Shiraishi T, Wada M. C-reactive protein concentration is more strongly related to metabolic syndrome in women than in men: the Minoh Study. Circ J. 2005;69(4):386-391.

29. Kondo N, Nomura M, Nakaya Y, Ito S, Ohguro T. Association of inflammatory marker and highly sensitive C-reactive protein with aerobic exercise capacity, maximum oxygen uptake and insulin resistance in healthy middle-aged volunteers. Circ J. 2005;69(4):452-457.

30. Berry C, Hamilton CA, Brosnan MJ, Magill FG, Berg GA, McMurray JJ, Dominiczak AF. Investigation into the sources of superoxide in human blood vessels: angiotensin II increases superoxide production in human internal mammary arteries. Circulation. 2000;101(18):22062212.

31. Hellsten-Westing Y. Immunohistochemical localization of xanthine oxidase in human cardiac and skeletal muscle. Histochemistry. 1993;100(3):215-222.

32. Muir SW, Harrow C, Dawson J, Lees KR, Weir CJ, Sat$\operatorname{tar}$ N, Walters MR. Allopurinol use yields potentially beneficial effects on inflammatory indices in those with recent ischemic stroke: a randomized, double-blind, placebo-controlled trial. Stroke. 2008;39(12):3303-3307. 